\title{
$\mathrm{Cu} / \mathrm{Sn}-3.5 \mathrm{Ag}$ 미세범프 구조에 따른 실시간 금속간화합물 성장거동 분석
}

\author{
이병록 ${ }^{1} \cdot$ 박종명 $^{2} \cdot$ 고영기 $^{3} \cdot$ 이창우 $^{3} \cdot$ 박영배 $^{1, \uparrow}$ \\ 1안동대학교 신소재공학부 청정에너지 소재기술 연구센터, ${ }^{2}$ Nepes Corporation, R\&D센터 \\ 3한국생산기술연구원 용접접합기술센터
}

\section{Effect of Solder Structure on the In-situ Intermetallic Compounds growth Characteristics of $\mathrm{Cu} / \mathrm{Sn}-3.5 \mathrm{Ag}$ Microbump}

\author{
Byeong-Rok Lee ${ }^{1}$, Jong-Myeong Park ${ }^{2}$, Young-Ki Ko ${ }^{3}$, Chang-Woo Lee ${ }^{3}$ and Young-Bae Park ${ }^{1, \dagger}$ \\ ${ }^{1}$ School of Materials Science and Engineering, Andong National University, Andong 760-749, Korea \\ ${ }^{2}$ NEPES Corporation, Cheongwon, 363-883, Korea \\ ${ }^{3}$ Micro-Joining Center, Korea Institute of Industrial Technology, Incheon 406-840, Korea \\ (2013년 9월 9일 접수: 2013년 9월 24일 수정: 2013년 9월 26일 게재확정)
}

\begin{abstract}
초 록: 3 차원 적층 패키지를 위한 $\mathrm{Cu} / \mathrm{Sn}-3.5 \mathrm{Ag}$ 미세범프의 솔더 구조에 따른 금속간화합물 성장거동을 분석하기 위 해 솔더 두께가 각각 $6 \mu \mathrm{m}, 4 \mu \mathrm{m}$ 인 서로 다른 구조의 미세범프를 $130^{\circ} \mathrm{C}, 150^{\circ} \mathrm{C}, 170^{\circ} \mathrm{C}$ 조건에서 실시간 주사전자현미경 을 이용하여 실시간 금속간화합물 성장 거동을 분석하였다. $\mathrm{Cu} / \mathrm{Sn}-3.5 \mathrm{Ag}(6 \mu \mathrm{m})$ 미세범프의 경우, 많은 양의 솔더로 인해

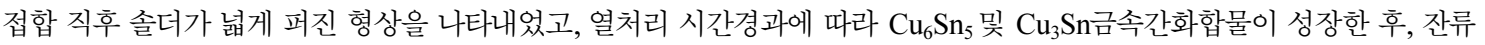
$\mathrm{Sn}$ 소모 시점 이후 $\mathrm{Cu}_{6} \mathrm{Sn}_{5}$ 가 $\mathrm{Cu}_{3} \mathrm{Sn}$ 으로 상전이 되는 구간이 존재하였다. 반면, $\mathrm{Cu} / \mathrm{Sn}-3.5 \mathrm{Ag}(4 \mu \mathrm{m})$ 미세범프의 경우, 적은 양의 솔더로 인해 접합 직후 솔더의 퍼짐 현상이 억제 되었고, 접합 직후 잔류 $\mathrm{Sn}$ 상이 존재하지 않아서 금속간화합물 성장 구간이 억제되고, 열처리 시간경과에 따라 $\mathrm{Cu}_{6} \mathrm{Sn}_{5}$ 가 $\mathrm{Cu}_{3} \mathrm{Sn}$ 으로 상전이 되는 구간만 존재하였다. 두 시편의 $\mathrm{Cu}_{3} \mathrm{Sn}$ 상의 활 성화 에너지의 값은 $\mathrm{Cu} / \mathrm{Sn}-3.5 \mathrm{Ag}(6 \mu \mathrm{m})$ 및 $\mathrm{Cu} / \mathrm{Sn}-3.5 \mathrm{Ag}(4 \mu \mathrm{m})$ 미세범프가 각각 $0.80 \mathrm{eV}, 0.71 \mathrm{eV}$ 로 나타났고, 이러한 차이 는 반응기구 구간의 차이에 따른 것으로 판단된다. 따라서, 솔더의 측면 퍼짐 보다는 접합 두께가 미세범프의 금속간화합 물 반응 기구를 지배하는 것으로 판단된다.
\end{abstract}

\begin{abstract}
Thermal annealing tests were performed in an in-situ scanning electron microscope chamber at $130^{\circ} \mathrm{C}, 150^{\circ} \mathrm{C}$, and $170^{\circ} \mathrm{C}$ in order to investigate the effects of solder structure on the growth kinetics of intermetallic compound (IMC) in $\mathrm{Cu} / \mathrm{Sn}-3.5 \mathrm{Ag}$ microbump. $\mathrm{Cu} / \mathrm{Sn}-3.5 \mathrm{Ag}(6 \mu \mathrm{m})$ microbump with spreading solder structure showed $\mathrm{Cu}_{6} \mathrm{Sn}_{5}$ and $\mathrm{Cu}_{3} \mathrm{Sn}$ phase growths and then IMC phase transition stages with increasing annealing time. By the way, $\mathrm{Cu} / \mathrm{Sn}-3.5 \mathrm{Ag}(4 \mu \mathrm{m})$ microbump without solder spreading, remaining solder was transformed to $\mathrm{Cu}_{6} \mathrm{Sn}_{5}$ right after bonding and had only a phase transition of $\mathrm{Cu}_{6} \mathrm{Sn}_{5}$ to $\mathrm{Cu}_{3} \mathrm{Sn}$ during annealing. Measured activation energies for the growth of the $\mathrm{Cu}_{3} \mathrm{Sn}$ phase during the annealing were 0.80 and $0.71 \mathrm{eV}$ for $\mathrm{Cu} / \mathrm{Sn}-3.5 \mathrm{Ag}(6 \mu \mathrm{m})$ and $\mathrm{Cu} / \mathrm{Sn}-3.5 \mathrm{Ag}(4 \mu \mathrm{m})$, respectively.
\end{abstract}

Keywords: microbump, solder structure, intermetallic compound, in-situ, activation energy

\section{1. 서 론}

최근 전자제품의 소형화 및 고성능화 추세에 따라 여 러 가지 기능의 칩을 통합할 수 있는 3 차원 칩 적층이 최 근 몇 년 동안 많은 관심을 끌고 있다. ${ }^{1-5)}$ 이러한 기술은 기존의 패키지들과 비교하여 부피와 무게를 최소화할 수 있고, 전력의 소모가 감소할 뿐만 아니라 고밀도화, 고기 능화를 이룰 수 있다. ${ }^{6}$ 이러한 고밀도, 고기능화를 이루
기 위해서는 피치의 미세화가 중요하다. 미세피치를 위 한 미세범프는 $\mathrm{Cu}$ pillar/솔더의 구조는 적은 양의 솔더를 사용하여 인접 범프와 접합을 유발하지 않고 미세 피치 를 적용할 수 있어 현재 주목받고 있다. 이러한 미세범프 는 $3 \mathrm{D} \mathrm{IC}$ 의 통합 패키지 시스템(SIP)에서, 와이어본딩에 서 $\mathrm{TSV}$ 를 통해 다른 고급 패키징 기술에 적용 할 수 있 기 때문에 미세범프가 많은 관심을 받고 있다. ${ }^{7)}$ 그러나 이러한 구조는 기존의 솔더 범프에 비해 상대적으로 적

${ }^{\dagger}$ Corresponding author

E-mail: ybpark@andong.ac.kr

(C) 2013, The Korean Microelectronics and Packaging Society

This is an Open-Access article distributed under the terms of the Creative Commons Attribution Non-Commercial License(http://creativecommons.org/ licenses/by-nc/3.0) which permits unrestricted non-commercial use, distribution, and reproduction in any medium, provided the original work is properly cited. 
은 양의 솔더로 접합부 계면에 취성 특성이 있는 조대한 금속간화합물(intermetallic compound, IMC) 및 Kirkendall void를 형성시켜 접합부의 전기적 및 기계적 신뢰성 저하 에 영향을 미치는 것으로 보고되고 있다. 811) $^{8-11}$

최근 연구에서는 다양한 $\mathrm{Cu}$ pillar 미세범프에서 열처 리에 따른 금속간화합물 성장 메커니즘 및 활성화 에너 지에 대한 연구가 보고 되고 있다. 우리 연구그룹에서 $\mathrm{Cu}$ pillar/pure $\mathrm{Sn}$ 에서 열처리 시 활성화 에너지를 $0.65 \mathrm{eV}$, 전 류인가조건에서는 $0.56 \mathrm{eV}$ 로 평가하였고, ${ }^{12)} \mathrm{Cu}$ pillar/ $\mathrm{Sn}$ $3.5 \mathrm{Ag}(6 \mathrm{um})$ 에서 열처리 시 활성화 에너지를 $0.68 \mathrm{eV}, \mathrm{Cu}$ pillar/ $\mathrm{Sn}-3.5 \mathrm{Ag}(4 \mathrm{um})$ 에서 열처리 시 $0.66 \mathrm{eV}$ 로 평가하였 다. ${ }^{713)}$ 또한 타 연구 그룹에서의 $\mathrm{Cu} / \mathrm{SnAg}$ 미세범프에서 의 활성화 에너지 값을 $0.73 \mathrm{eV}$ 로 평가하였고, ${ }^{14)} \mathrm{SnAgCu} /$ $\mathrm{Cu}$ 솔더 범프에서의 활성화 에너지 값은 $0.65 \mathrm{eV}$ 로 평가 하였다. ${ }^{15)}$ 그러나 서로 다른 구조를 가진 $\mathrm{Cu} / \mathrm{Sn} 3.5 \mathrm{Ag}$ 미 세범프의 금속간화합물 성장 메커니즘을 실시간 정량적 평가 및 활성화 에너지를 도출한 연구가 많이 이루어지 지 않았다.

따라서 본 연구에서는 실시간 주사전자현미경(in-situ scanning electron microscopy (SEM))을 이용하여 $\mathrm{Cu} / \mathrm{Sn}$ $3.5 \mathrm{Ag}$ 미세범프의 솔더 구조에 따른 금속간화합물 성장 거동을 분석하기 위해 솔더 두께가 각각 $6 \mu \mathrm{m}, 4 \mu \mathrm{m}$ 인 서 로 다른 구조의 미세범프를 $130^{\circ} \mathrm{C}, 150^{\circ} \mathrm{C}, 170^{\circ} \mathrm{C}$ 조건에 서 실시간 금속간화합물 성장 거동을 분석하고, 활성화 에너지를 도출하였다.

\section{2. 실험 방법}

$\mathrm{Cu} / \mathrm{Sn}-3.5 \mathrm{Ag}$ 미세범프의 솔더 구조에 따른 금속간화합 물 성장 거동을 분석하기 위해 솔더 두께가 각각 $6 \mu \mathrm{m}$, $4 \mu \mathrm{m}$ 인 서로 다른 구조의 미세범프를 $130^{\circ} \mathrm{C}, 150^{\circ} \mathrm{C}$, $170^{\circ} \mathrm{C}$ 조건에서 in-situ $\mathrm{SEM}$ 을 이용하여 실시간 금속간 화합물 성장 거동을 분석하였다. 본 연구에 사용된 $\mathrm{Cu} /$ $\mathrm{Sn}-3.5 \mathrm{Ag}(6 \mu \mathrm{m})$ 미세범프와 $\mathrm{Cu} / \mathrm{Sn}-3.5 \mathrm{Ag}(4 \mu \mathrm{m})$ 미세범프 구조의 모식도를 Fig. 1 (a), (b)로 나타내었다. Si로 구성 된 하부 칩에 sputter를 이용하여 Ti seed layer를 형성하 고 전기도금을 통하여 약 $5 \mu \mathrm{m}$ 두께 및 약 $40 \mu \mathrm{m}$ 지름을 갖는 $\mathrm{Cu}$ pillar를 형성하였다. 상부 기판 또한 전기도금을 이용하여 $10 \mu \mathrm{m}$ 두께 및 약 $20 \mu \mathrm{m}$ 지름을 갖는 $\mathrm{Cu}$ pillar 를 형성하였으며, 그 위에 약 $6 \mu \mathrm{m}$ 와 $4 \mu \mathrm{m}$ 두께의 Sn$3.5 \mathrm{Ag}$ 솔더를 전기도금으로 형성하였고, $260^{\circ} \mathrm{C}$ 에서 약 $20 \mathrm{~N}$ 의 압력으로 플립칩 본딩(flip-chip bonding)으로 접합 하였다. 열처리에 따른 금속간화합물의 형성 및 성장을 실시간으로 관찰하기 위해 시편을 \#600 \#2000의 연마 지와 1 3 $\mu \mathrm{m}$ 의 연마천 및 연마액을 이용하여 단면 폴리 싱 후, 각각 $130^{\circ} \mathrm{C}$ 와 $150^{\circ} \mathrm{C}, 170^{\circ} \mathrm{C}$ 의 조건에서 실험을 진 행하였다. 열처리에 따른 솔더 접합부의 금속간화합물 형 성과 성장을 관찰하기 위하여 in-situ $\mathrm{SEM}$ 의 back scattered electron (BSE)사진과 energy dispersive x-ray spectroscopy

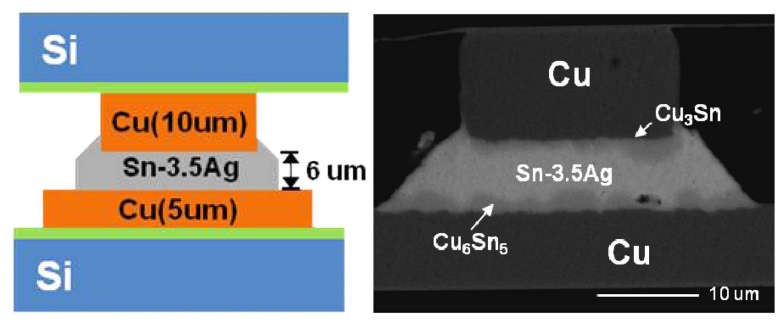

(a)
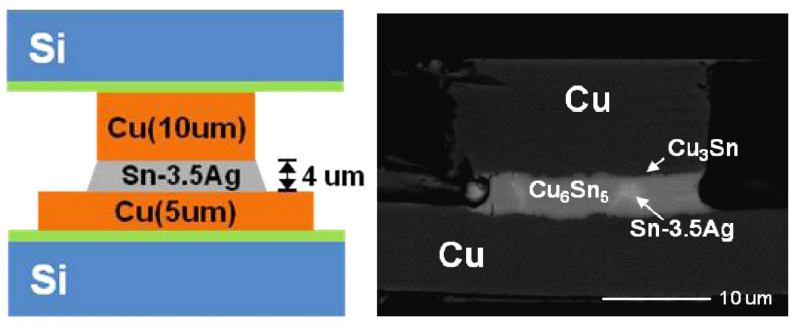

(b)

Fig. 1. Schematic diagram and cross-sectional SEM images of (a) $\mathrm{Cu} /$ $\mathrm{Sn}-3.5 \mathrm{Ag}(6 \mu \mathrm{m})$ microbump with spreading solder structure (structure A) and (b) $\mathrm{Cu} / \mathrm{Sn}-3.5 \mathrm{Ag}(4 \mu \mathrm{m})$ microbump without solder spreading (structure B).

(EDS)를 이용하여 실시간으로 분석하였다. 금속간화합 물의 두께는 칩 양단에 형성된 금속간화합물 층을 측정 하였고, image analyzer를 이용하여 솔더 두께 및 열처리 온도에 따른 금속간화합물의 두께 변화를 정량화하였다. 그 결과를 통하여 금속간화합물의 성장 거동 및 활성화 에너지를 비교 평가하였다.

\section{3. 결과 및 고찰}

온도에 따른 서로 다른 구조를 가진 $\mathrm{Cu} / \mathrm{Sn}-3.5 \mathrm{Ag}$ 미세 범프의 금속간화합물 형성과 성장 거동을 관찰하기 위해 각각 $130^{\circ} \mathrm{C}$ 와 $150^{\circ} \mathrm{C}, 170^{\circ} \mathrm{C}$ 의 조건에서 일정한 시간 동 안 열처리를 시행하였다. Fig. 1은 $\mathrm{Cu} / \mathrm{Sn}-3.5 \mathrm{Ag}(6 \mu \mathrm{m})$ 미 세범프와 $\mathrm{Cu} / \mathrm{Sn}-3.5 \mathrm{Ag}(4 \mu \mathrm{m})$ 미세범프의 접합직후 $\mathrm{SEM}$ 이미지이다. $\mathrm{Cu} / \mathrm{Sn}-3.5 \mathrm{Ag}(6 \mu \mathrm{m})$ 의 경우 많은 양의 솔더로 인해 접합 직후 솔더가 넓게 퍼짐 형상을 나타내었고, $\mathrm{Cu} /$ $\mathrm{Sn}-3.5 \mathrm{Ag}(4 \mu \mathrm{m})$ 의 경우 적은 양의 솔더로 인해 접합 직후 솔더의 퍼짐 현상이 억제 되었다. 이러한 형상의 차이로 인해 솔더가 퍼진 $\mathrm{Cu} / \mathrm{Sn}-3.5 \mathrm{Ag}(6 \mu \mathrm{m})$ 미세범프를 structure $\mathrm{A}$, 솔더의 퍼짐이 억제된 $\mathrm{Cu} / \mathrm{Sn}-3.5 \mathrm{Ag}(4 \mu \mathrm{m})$ 미세범프를 structure B로 명명하였다.

Fig. 1(a)는 structure A 미세범프의 접합 직후 SEM 이 미지로, $\mathrm{EDS}$ 분석 결과 접합 직후 $\mathrm{Cu}$ pillar와 솔더의 접 합 계면에서 솔더 내부로 얇은 $\mathrm{Cu}_{3} \mathrm{Sn}$ 상과 두꺼운 $\mathrm{Cu}_{6} \mathrm{Sn}_{5}$ 상이 형성되는 것을 관찰할 수 있다. 두꺼운 $\mathrm{Cu}_{6} \mathrm{Sn}_{5}$ 상이 형성되는 것은 석출구동력이 큰 상일수록 먼저 석출이 되 는데, 이때 금속간화합물 중 $\mathrm{Cu}_{6} \mathrm{Sn}_{5}$ 상의 표면 반응속도 가 더 빠르다는 것을 보여주며 금속간화합물 석출구동력 이 크다는 것을 알 수 있다. ${ }^{16)}$ 여기서 $\mathrm{Cu}_{6} \mathrm{Sn}_{5}$ 상이 좁고 둥 
근 기둥 형태의 가리비형상(scallop type)으로 형성된 것 을 확인할 수 있다. 이것은 깁스-톰슨(Gibbs-Thompson)효 과로 설명된다. 금속간화합물 결정립의 곡률반경에 의한 용해도 차이가 발생하여 작은 결정립의 원자들이 큰 결 정립으로 이동하기 때문이다. ${ }^{17)}$ 이때 금속간화합물의 두 께 증가는 $\mathrm{Cu}$ 원자의 솔더 내 확산기구에 의존한다. 그 러나, Fig. 1(b)의 structure B 미세범프는 $\mathrm{Sn}$ 층이 얇기 때 문에 접합 공정 중 $\mathrm{Sn}-\mathrm{Cu}$ 금속간화합물의 성장이 계속적 이지 못하고 서로 맞닿게 된다. 이에 따라 Fig. 1(b)에서 나타나는 갇힌 형태의 $\mathrm{Sn}$ 아일랜드가 형성되고, $\mathrm{Sn}$ 의 제 한된 공급으로 인해 $\mathrm{Cu}_{6} \mathrm{Sn}_{5}$ 상의 성장이 매우 둔해진다. $\mathrm{Sn}$ 의 공급은 제한되지만 $\mathrm{Cu}$ 원자의 확산은 계속 이루어 지므로, $\mathrm{Cu} / \mathrm{Cu}_{6} \mathrm{Sn}_{5}$ 불평형 계면 사이에서 $\mathrm{Cu}_{6} \mathrm{Sn}_{5}$ 상이 $\mathrm{Cu}_{3} \mathrm{Sn}$ 상으로 상전이가 일어난다. 이때의 반응식 (1)은 다 음과 같다.

$$
\mathrm{Cu}_{6} \mathrm{Sn}_{5}+9 \mathrm{Cu} \rightarrow 5 \mathrm{Cu}_{3} \mathrm{Sn}
$$

Fig. 2는 structure A 미세범프의 열처리 시간에 따른 계 면에서의 미세구조 변화를 보여준다. $130^{\circ} \mathrm{C}$ 에서 열처리 시간경과에 따라 $\mathrm{Cu}_{6} \mathrm{Sn}_{5}$ 상과 $\mathrm{Cu}_{3} \mathrm{Sn}$ 상이 성장하는 것을 확인할 수 있었고, $220 \mathrm{~h}$ 후에도 계속해서 솔더가 남아있 는 것을 확인할 수 있었다. $150^{\circ} \mathrm{C}$ 에서는 $130^{\circ} \mathrm{C}$ 와 같이 $\mathrm{Cu}_{6} \mathrm{Sn}_{5}$ 상과 $\mathrm{Cu}_{3} \mathrm{Sn}$ 상이 눈에 띄게 증가하는 것을 확인할 수 있었다. 그러나 $300 \mathrm{~h}$ 이후 잔류 솔더가 모두 $\mathrm{Cu}$ 와 반 응하여 $\mathrm{Cu}_{6} \mathrm{Sn}_{5}$ 상을 형성하였고, 이후 열처리 시간경과에 따라 계속된 $\mathrm{Cu}$ 의 유입으로 인해 $\mathrm{Cu}_{6} \mathrm{Sn}_{5}$ 상이 $\mathrm{Cu}_{3} \mathrm{Sn}$ 상으 로 상전이 되었다. $170^{\circ} \mathrm{C}$ 에서는 $100 \mathrm{~h}$ 까지 $\mathrm{Cu}$ 와 $\mathrm{Sn}$ 이 반 응하여 $\mathrm{Cu}_{6} \mathrm{Sn}_{5}$ 상이 급격하게 증가하였으며, 이 후 잔류 $\mathrm{Sn}$ 이 모두 소모되어 $\mathrm{Cu}_{6} \mathrm{Sn}_{5}$ 상은 더 이상 성장하지 않고, $\mathrm{Cu}_{6} \mathrm{Sn}_{5}$ 상이 $\mathrm{Cu}_{3} \mathrm{Sn}$ 상으로 상전이 되는 것을 확인할 수 있 었다. 또한, 열처리 $220 \mathrm{~h}$ 이후에는 $\mathrm{Cu}_{6} \mathrm{Sn}_{5}$ 상이 $\mathrm{Cu}_{3} \mathrm{Sn}$ 상으
로 상전이 되어 미량의 $\mathrm{Cu}_{6} \mathrm{Sn}_{5}$ 상만이 관찰되었다. 기 보 고에 의하면 Kirkendall void는 $\mathrm{Cu}$ 와 $\mathrm{Sn}$ 원자 간의 불균 일한 확산 속도로 인해 발생하는 현상으로 $\mathrm{Sn}$ 원자보다 $\mathrm{Cu}$ 원자의 확산 속도가 더 빠르므로 $\mathrm{Cu} / \mathrm{Cu}_{3} \mathrm{Sn}$ 계면과 $\mathrm{Cu}_{3} \mathrm{Sn}$ 내부에 발생한다고 알려져 있다. ${ }^{18)}$ 본 연구에서 또 한 Kirkendall void가 관찰되었으며, 이는 접합직후보다 열처리 온도가 높고, 시간경과에 따라 증가 되는 것을 확 인하였다. Fig. 3은 structure A 미세범프의 열처리 시간에 따른 금속간화합물 $\left(\mathrm{Cu}_{6} \mathrm{Sn}_{5}, \mathrm{Cu}_{3} \mathrm{Sn}\right)$ 및 $\mathrm{Sn}-3.5 \mathrm{Ag}$ 의 성장거 동을 나타낸 그래프이다. 이때 금속간화합물의 두께는 $\mathrm{Cu}$ pillar와 솔더, $\mathrm{Cu}$ pad와 솔더 두 계면 모두에서 성장 하는 금속간 화합물 두께의 합으로 나타내었으며, 금속 간화합물의 두께와 열처리 시간의 관계는 식(2)의 방정식 을 통하여 간단히 나타낼 수 있다.

$$
\mathrm{d}_{\mathrm{IMC}}=\mathrm{kt}^{\mathrm{n}}
$$

여기서, $\mathrm{d}_{\mathrm{IMC}}$ 는 $\mathrm{IMC}$ 의 두께, $\mathrm{k}$ 는 반응 상수, $\mathrm{t}$ 는 시간, 그리고 $\mathrm{n}$ 은 반응 지수를 나타낸다.

Fig. 3에서 볼 수 있듯이 금속간화합물의 성장 거동은 열처리 시간경과에 따라 시간의 제곱근 $(\mathrm{n}=0.5)$ 의 직선 형 태로 증가하여, $\mathrm{Cu}-\mathrm{Sn}$ 금속간화합물의 성장은 확산지배기 구로 판단된다. 그러나 Fig. 3(b), (c)에서는 각각 200h, 60h

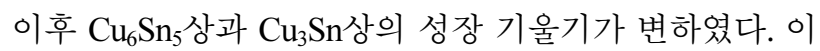
는 모든 솔더가 $\mathrm{Cu}_{6} \mathrm{Sn}_{5}$ 상이 되는 시점에서 나타나고, 이 후 $\mathrm{Cu}$ pillar에서 계속해서 공급된 $\mathrm{Cu}$ 원자에 의해 $\mathrm{Cu}_{6} \mathrm{Sn}_{5}$ 상이 $\mathrm{Cu}_{3} \mathrm{Sn}$ 상으로 상전이가 일어나기 때문이라 판단된 다. 금속간화합물의 성장 속도가 변하게 되는 시점에 대 하여 다음과 같이 정의하였다. $\mathrm{Sn}$ 을 소모하며 $\mathrm{Cu}_{6} \mathrm{Sn}_{5}$ 상 이 빠르게 성장하는 구간을 "stage 1 ", $\mathrm{Sn}$ 이 완전히 소모 되는 시점을 "transition time", $\mathrm{Sn}$ 을 완전히 소모한 후 $\mathrm{Cu}_{6} \mathrm{Sn}_{5}$ 에서 $\mathrm{Cu}_{3} \mathrm{Sn}$ 으로 상전이만 일어나는 구간을 "stage
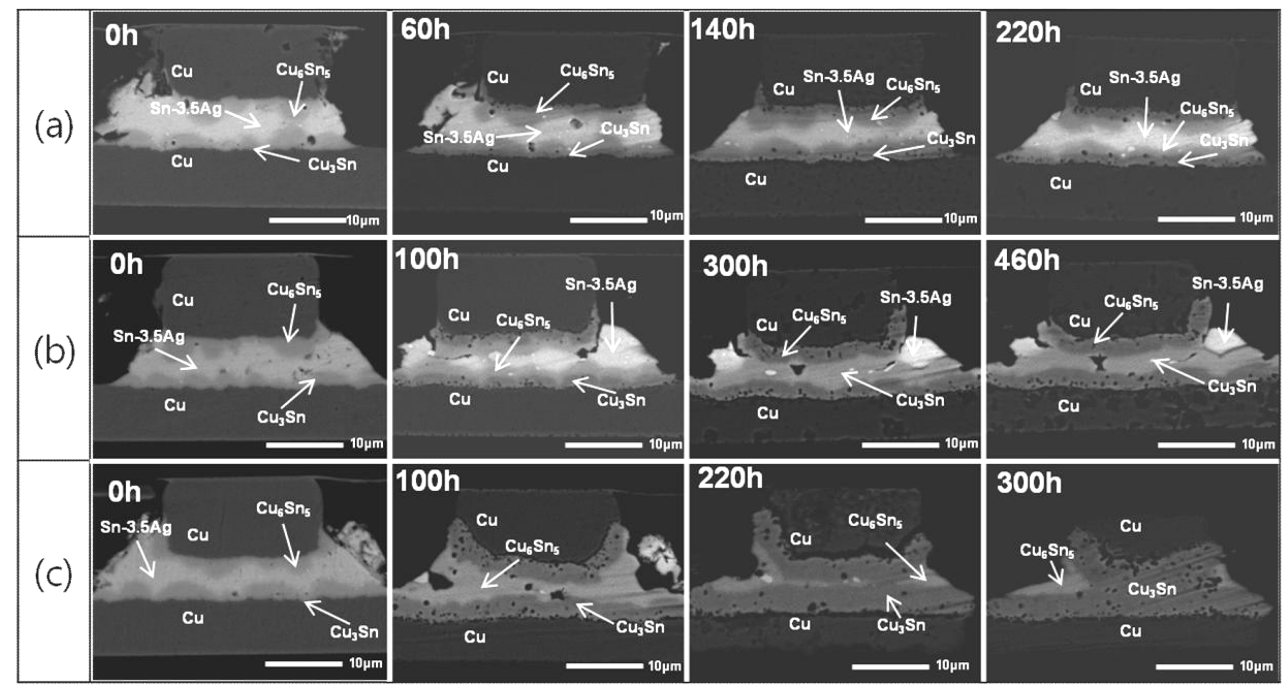

Fig. 2. In-situ SEM images of the cross-sectioned bonding interface of structure A microbump during annealing at; (a) $130^{\circ} \mathrm{C}$, (b) $150^{\circ} \mathrm{C}$, (c) $170^{\circ} \mathrm{C}$. 


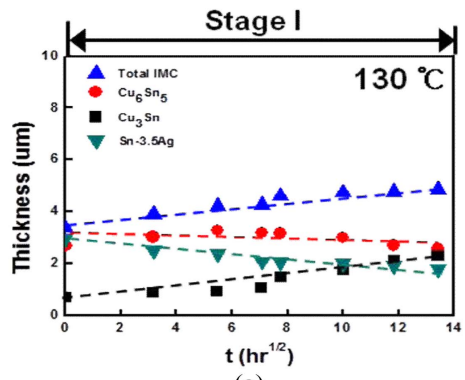

(a)

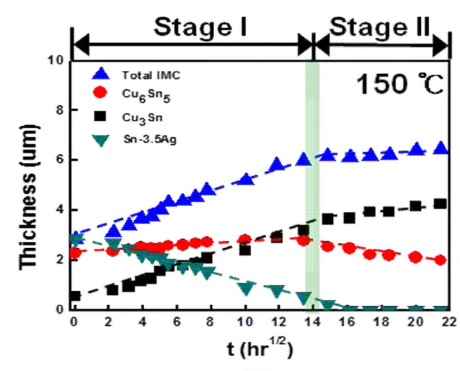

(b)

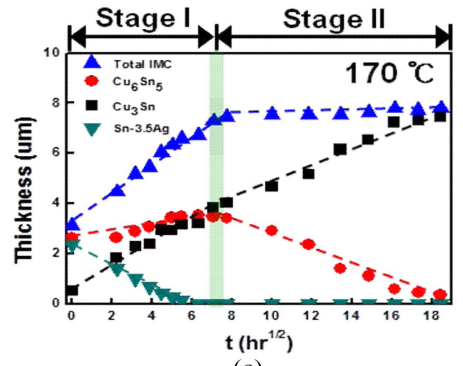

(c)

Fig. 3. Thickness variations of each IMC phase of structure A microbump as a function of annealing time at (a) $130^{\circ} \mathrm{C}$, (b) $150^{\circ} \mathrm{C}$, and (c) $170^{\circ} \mathrm{C}$.

2”라 명명 하였다. ${ }^{19)}$

Fig. 4는 structure B 미세범프의 열처리 시간에 따른 계 면에서의 미세구조 변화를 보여준다. structure B 미세범 프는 structure A 미세범프보다 얇은 솔더의 두께로 인해 접합 직후부터 솔더가 남아 있지 않고, $\mathrm{Cu}_{6} \mathrm{Sn}_{5}$ 상으로 반 응한 것을 확인할 수 있다. 또한, 접합 후 단면 이미지에 서 microvoid가 관찰되는데, 이는 접합 시 남아있던 플럭 스(flux)가 빠져나가면서 생기는 것으로 보인다. $130^{\circ} \mathrm{C}$ 에 서는 접합직후 적은양의 솔더가 잔류하고 있었지만, 열 처리 시간경과에 따라 잔류 솔더가 모두 소모되어 $\mathrm{Cu}_{6} \mathrm{Sn}_{5}$ 상으로 바뀌었다. $10 \mathrm{~h}$ 이후부터 $\mathrm{Cu}_{6} \mathrm{Sn}_{5}$ 상에서 $\mathrm{Cu}_{3} \mathrm{Sn}$ 상으 로 상전이가 일어났다. $150^{\circ} \mathrm{C}$ 와 $170^{\circ} \mathrm{C}$ 에서는 각각 열처 리 $180 \mathrm{~h}, 60 \mathrm{~h}$ 이후 $\mathrm{Cu}_{6} \mathrm{Sn}_{5}$ 상은 관찰되지 않았으며, 식(1) 과 같이 모든 $\mathrm{Cu}_{6} \mathrm{Sn}_{5}$ 상이 $\mathrm{Cu}_{3} \mathrm{Sn}$ 상으로 상전이 된 것을 확 인할 수 있다. Kirkendall void는 structure $\mathrm{A}$ 미세범프와 유 사하게 생성되는 것을 확인할 수 있었다.

Fig. 5는 structure B 미세범프의 온도 인가 시간에 따른 금속간화합물 $\left(\mathrm{Cu}_{6} \mathrm{Sn}_{5}, \mathrm{Cu}_{3} \mathrm{Sn}\right)$ 의 성장 거동을 나타낸 그래 프이며, 이때 금속간화합물의 두께와 시간의 관계는 식 (2)의 방정식을 통하여 간단히 나타내었다. structure B 미
세범프는 structure A 미세범프와 달리 적은 양의 솔더로 인해 접합 직후 모든 솔더가 $\mathrm{Cu}_{6} \mathrm{Sn}_{5}$ 상으로 바뀌어 $\mathrm{Cu}_{6} \mathrm{Sn}_{5}$ 상이 증가하는 stage 1 구간은 존재하지 않고, 상전이가 일 어나는 stage 2구간만이 존재하였다.

각 온도별 structure A 미세범프와 structure B 미세범프 에서 주성장상인 $\mathrm{Cu}_{3} \mathrm{Sn}$ 상에 대하여 열처리 조건에 따른 활성화 에너지를 구할 수 있다. 이때, 활성화 에너지는 식 (3)의 Arrhenius 방정식을 이용하여 계산할 수 있다.

$$
\mathrm{k}^{2}=\mathrm{k}_{0}^{2} \exp \left(-\frac{\mathrm{E}_{\mathrm{a}}}{\mathrm{RT}}\right)
$$

여기서, $\mathrm{k}^{2}$ 은 반응상수의 제곱, $\mathrm{k}_{0}^{2}$ 은 frequency factor, $\mathrm{Ea}$ 는 활성화 에너지, $\mathrm{R}$ 은 기체상수 그리고 $\mathrm{T}$ 는 열처리 온 도를 나타낸다. 이에 따른 $\mathrm{Cu}_{3} \mathrm{Sn}$ 상의 활성화 에너지를 계 산하였다. Structure A 미세범프의 경우 $\mathrm{Cu}_{3} \mathrm{Sn}$ 상이 transition time을 지나면서 기울기가 변하기 때문에 stage 1의 $\mathrm{Cu}_{3} \mathrm{Sn}$ 상의 활성화 에너지를 도출하였다. 그러나 structure $\mathrm{B}$ 미세범프의 경우 접합 직후부터 stage 2구간만이 존재 하므로 이 구간에서의 $\mathrm{Cu}_{3} \mathrm{Sn}$ 상의 활성화 에너지를 도출 하였다. 그 결과 structure A 미세범프와 structure B 미세
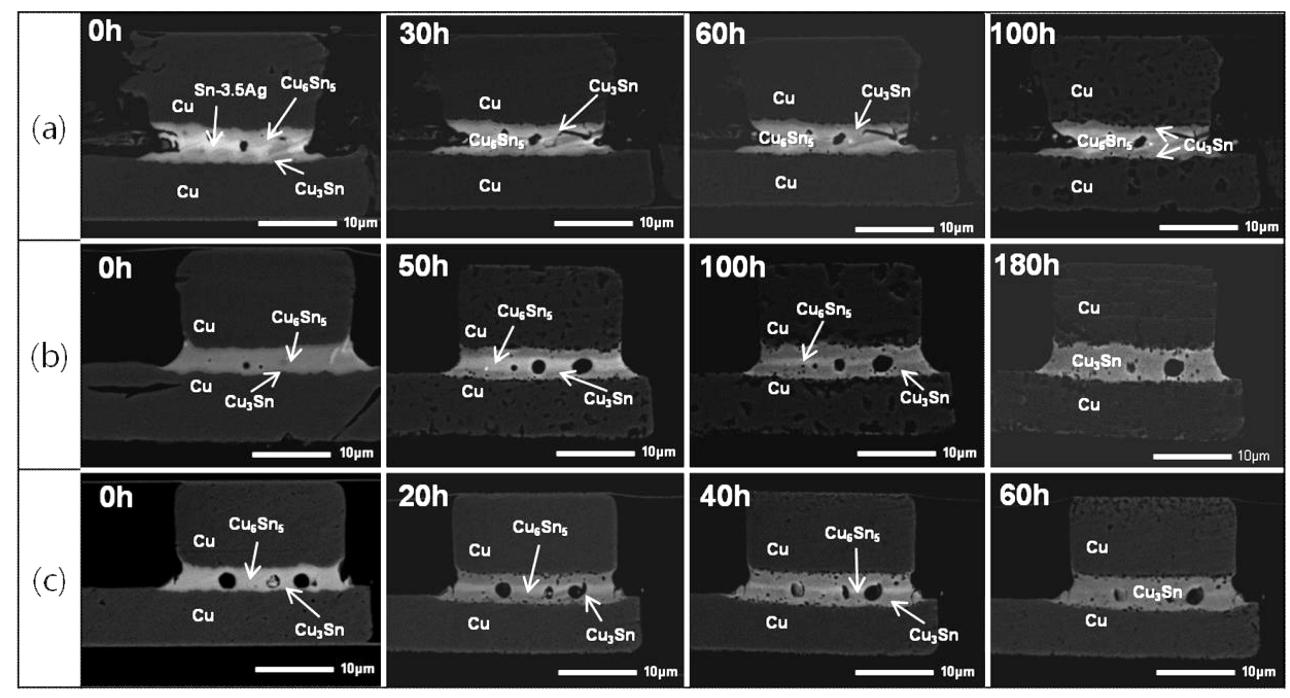

Fig. 4. In-situ SEM images of the cross-sectioned bonding interface of structure B microbump during annealing at; (a) $130^{\circ} \mathrm{C}$, (b) $150^{\circ} \mathrm{C}$, (c) $170^{\circ} \mathrm{C}$. 


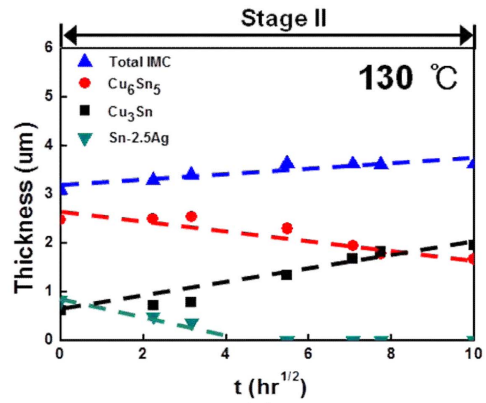

(a)

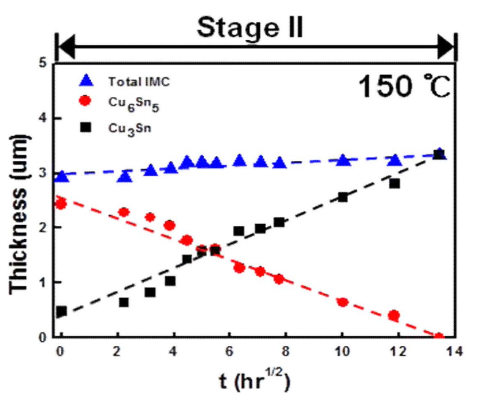

(b)

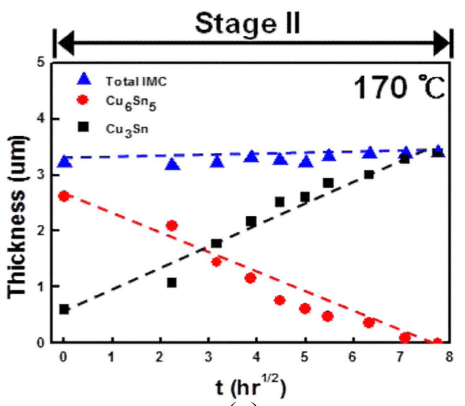

(c)

Fig. 5. Thickness variations of each IMC phase of structure B microbump as a function of annealing time at (a) $130^{\circ} \mathrm{C}$, (b) $150^{\circ} \mathrm{C}$, and (c) $170^{\circ} \mathrm{C}$.

범프의 활성화 에너지는 각각 $0.8 \mathrm{eV}$ 와 $0.71 \mathrm{eV}$ 로 평가되 었고, Fig 6에 나타내었다.

우리 연구 그룹에서는Cu pillar/pure $\mathrm{Sn}(2-3 \mathrm{um})$ 구조를 $125^{\circ} \mathrm{C}, 150^{\circ} \mathrm{C}, 175^{\circ} \mathrm{C}$ 조건에서 열처리 시 $\mathrm{Cu}_{3} \mathrm{Sn}$ 상의 stage 1 구간에서 활성화 에너지는 $0.65 \mathrm{eV}$, 동일 온도조건에서 전류밀도 $2.2 \times 10^{4} \mathrm{~A} / \mathrm{cm}^{2}$ 인가 시 $0.56 \mathrm{eV}$ 로 평가되었다. ${ }^{12)}$ 또한 $\mathrm{Cu}$ pillar/ $\mathrm{Sn}-3.5 \mathrm{Ag}(6 \mathrm{um})$ 구조를 $120^{\circ} \mathrm{C}, 150^{\circ} \mathrm{C}, 175^{\circ} \mathrm{C}$ 조건에서 열처리 시 $\mathrm{Cu}_{3} \mathrm{Sn}$ 상의 활성화 에너지는 $0.68 \mathrm{eV}$, $\mathrm{Cu}$ pillar/ $\mathrm{Sn}-3.5 \mathrm{Ag}(4 \mathrm{um})$ 구조에서 동일 온도조건에서 열 처리 시 $0.66 \mathrm{eV}$ 로 평가되었다. ${ }^{713)}$ 타 연구 그룹에서는 $\mathrm{Cu} / \mathrm{SnAg}$ 플립칩 솔더범프 구조에서 $110 \sim 208^{\circ} \mathrm{C}$ 열처리 시 $\mathrm{Cu}_{3} \mathrm{Sn}$ 상의 활성화 에너지 값이 $0.73 \mathrm{eV}$ 로 평가되었으 며, ${ }^{14)} \mathrm{SnAgCu} / \mathrm{Cu}$ 플립칩 솔더범프 구조에서 $100 \sim 200^{\circ} \mathrm{C}$ 열처리 시 $\mathrm{Cu}_{3} \mathrm{Sn}$ 상의 활성화 에너지 값이 $0.83 \mathrm{eV}$ 로 평가 되었다. ${ }^{15)}$ 이러한 결과를 바탕으로 구조가 다른 시편의 열처리에 따른 활성화 에너지를 비교해보면, 플립칩 솔 더범프 구조에서는 $\mathrm{Cu}$ pillar 범프 보다 상대적으로 많은 $\mathrm{Sn}$ 의 양으로 인해 $\mathrm{Cu}$ 와 $\mathrm{Sn}$ 의 계면에서 $\mathrm{Cu}_{6} \mathrm{Sn}_{5}$ 상의 성장 이 지배적인 반응을 나타내고, $\mathrm{Cu}$ pillar 범프 구조는 보 다 적은 양의 $\mathrm{Sn}$ 으로 인해 접합 시 $\mathrm{Cu}_{6} \mathrm{Sn}_{5}$ 상의 성장이 지 배적이며 열처리 시 $\mathrm{Cu}_{6} \mathrm{Sn}_{5}$ 상에서 $\mathrm{Cu}_{3} \mathrm{Sn}$ 상으로의 상전 이 반응이 지배적이다. 이처럼 플립칩 솔더 범프와 $\mathrm{Cu}$ pillar 범프에서는 금속간화합물의 성장에 지배적인 반응 이 다르므로 활성화 에너지의 값에 차이가 발생한 것으 로 판단된다. ${ }^{19-21)}$

그러나 이번 실험에서는 같은 $\mathrm{Cu}$ pillar구조에서도 솔 더 두께 및 퍼짐 여부에 따라 활성화 에너지의 값에 차이 가 있었다. 그러나 이 또한 Fig. 7의 모식도에서 나타내듯 이 시편의 접합 직후 미세구조의 차이에서 비롯된 것으 로 판단된다. Structure $\mathrm{A}$ 미세범프의 경우 많은 솔더의 양 으로 인해 접합 직후 Fig. 7(a), (b)와 같이 솔더 부분이 남 아있지만, structure B미세범프의 경우 Fig. 7(b), (c)와 같 이 접합 직후 솔더 부분은 남아있지 않고, 모두 $\mathrm{Cu}_{6} \mathrm{Sn}_{5}$ 상 으로 변하였다. 그로 인해 structure A 미세범프에서는 열 처리를 하는 동안 솔더를 소모하며 계속해서 $\mathrm{Cu}_{6} \mathrm{Sn}_{5}$ 상이 성장하게 되고, structure B 미세범프는 열처리를 하는 동 안 잔류 솔더가 남아있지 않아 $\mathrm{Cu}_{6} \mathrm{Sn}_{5}$ 상에서 $\mathrm{Cu}_{3} \mathrm{Sn}$ 상으

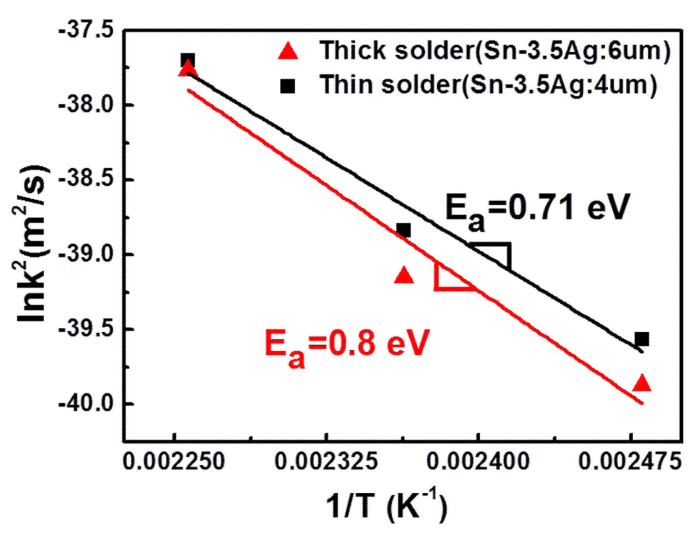

Fig. 6. Arrhenius plot of $\mathrm{Cu}_{3} \mathrm{Sn}$ growth rate of structure $\mathrm{A}$ and structure B microbumps.

로 상전이만 하게 됨으로써 활성화 에너지의 값이 차이 나는 것으로 판단된다. 솔더의 퍼짐 여부에 따라, 솔더가 $\mathrm{Cu}$ 와 접하는 면적의 차이로 인해 금속간화합물이 생성되 는 양의 차이는 있었지만 금속간화합물의 두께에는 큰 차 이가 없었다. 이 때문에 솔더의 퍼짐 여부는 활성화 에너 지 값에 큰 영향을 미치지 못하였다. 따라서 솔더의 퍼짐 보다는 접합 시 솔더의 두께가 미세범프의 금속간화합물 성장에 영향을 미치는것으로 판단된다.

\section{3. 결 론}

$\mathrm{Cu} / \mathrm{Sn}-3.5 \mathrm{Ag}$ 미세범프의 솔더 두께 및 퍼짐 여부에 따 른 금속간화합물의 성장거동을 in-situ SEM을 이용하여 분석하였다. 금속간화합물의 성장거동은 열처리 시간이 경과함에 따라 시간 제곱근에 직선 형태로 증가하여, $\mathrm{Cu}-$ $\mathrm{Sn}$ 금속간화합물의 성장은 확산지배기구로 판단된다. 솔 더 퍼짐 구조를 갖는 $\mathrm{Cu} / \mathrm{Sn}-3.5 \mathrm{Ag}(6 \mu \mathrm{m})$ 미세범프의 경우 초기에는 $\mathrm{Cu}$ 와 반응할 수 있는 $\mathrm{Sn}$ 양이 충분하여 $\mathrm{Cu}_{6} \mathrm{Sn}_{5}$ 상의 성장반응이 우세하였지만, 잔류 $\mathrm{Sn}$ 이 완전 소모된 후 $\mathrm{Cu}_{6} \mathrm{Sn}_{5}$ 상이 $\mathrm{Cu}_{3} \mathrm{Sn}$ 상으로 바뀌는 상전이 반응이 우세 하였다. 반면, 솔더 퍼짐이 억제된 $\mathrm{Cu} / \mathrm{Sn}-3.5 \mathrm{Ag}(4 \mu \mathrm{m})$ 미 세범프의 경우에는 접합 직후 잔류 솔더가 모두 $\mathrm{Cu}_{6} \mathrm{Sn}_{5}$ 상으로 변하여, $\mathrm{Sn}$ 소모가 필요한 $\mathrm{Cu}_{6} \mathrm{Sn}_{5}$ 상 증가 구간은 


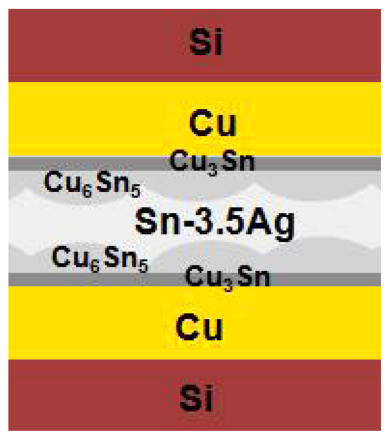

(a)

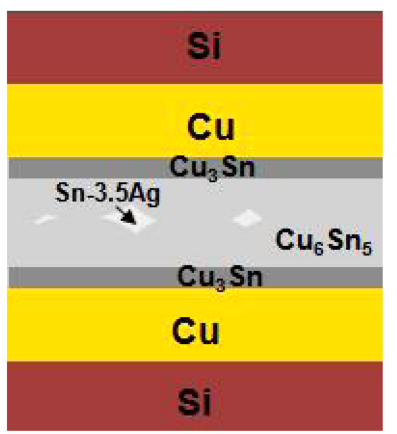

(b)

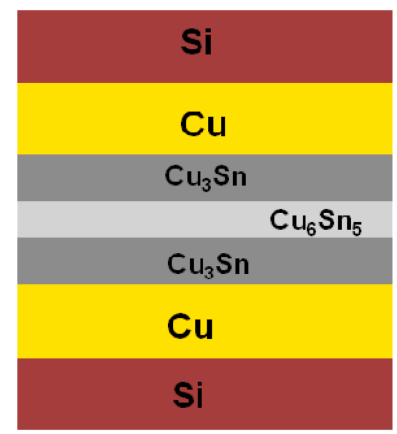

(c)

Fig. 7. Schematic of the $\mathrm{Cu}-\mathrm{Sn}$ reaction mechanism of $\mathrm{Cu} / \mathrm{Sn}-3.5 \mathrm{Ag}(6 \mu \mathrm{m}$ thick $)$ microbump during annealing.

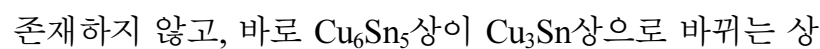
전이 반응만 존재하였다. 이러한 계면반응기구 구간 차 이로 인해 $\mathrm{Cu} / \mathrm{Sn}-3.5 \mathrm{Ag}(6 \mu \mathrm{m})$ 미세범프의 경우 $0.8 \mathrm{eV}$ 의 활성화 에너지 값으로 평가 되었고, $\mathrm{Cu} / \mathrm{Sn}-3.5 \mathrm{Ag}(4 \mu \mathrm{m})$ 미세범프는 $0.71 \mathrm{eV}$ 의 활성화 에너지 값으로 차이가 나타 났다. 따라서, 솔더의 측면 퍼짐 보다는 접합 두께가 미 세범프의 금속간화합물 반응기구를 지배하는 것으로 판 단된다.

\section{감사의 글}

본 논문은 지식경제부 산하 산업기술연구회가 지원하 는 협동과제의 지원과 지식경제부 국가플랫폼기술개발 사업의 일환으로 수행되었으며, 이에 감사 드립니다.

\section{참고문헌}

1. J. S. Ha, J. P. Jung and T. S. Oh, "Effects of Intermetallic Compounds Formed during Flip Chip Process on the Interfacial Reactions and Bonding Characteristics", J. Microelectron. Packag. Soc., 19(2), 35 (2012).

2. S. C. Park, K. J. Min, K. H. Lee, Y. S. Jeong and Y. B. Park, "Effect of Annealing on the Interfacial Adhesion Energy between Electroless-Plated Ni and Polyimide", Met. Mater. Int., 17, 111 (2011).

3. E. J. Jang, J. W. Kim, B. Kim, T. Matthias and Y. B. Park, "Annealing Temperature Effect on the $\mathrm{Cu}-\mathrm{Cu}$ Bonding Energy for 3D-IC Integration”, Met. Mater. Int., 17, 105 (2011).

4. K. N. Chen, C. S. Tan, A. Fan and R. Reif, "Abnormal Contact Resistance Reduction of Bonded Copper Interconnects in Three-Dimensional Integration during Current Stressing”, Appl. Phys. Lett., 86, 011903 (2005).

5. M. Murugesan, Y. Ohara, T. Fukushima, T. Tanaka and M. Koyanagi, "Low-Resistance Cu-Sn Electroplated-Evaporated Microbumps for 3D Chip Stacking”, J. Electron. Mater., 41, 4 (2012).

6. H. H. Kim, D. H. Kim, J. B. Kim, H. J. Kim, J. U. Ahn, I. S. Kang, J. K Lee, H. S. Ahn and S. D. Kim, "The Effects of UBM and $\mathrm{SnAgCu}$ Solder on Drop Impact Reliability of
Wafer Level Package”, J. Microelectron. Packag. Soc., 17(3), 65 (2010).

7. B. H. Kwak, M. H. Jeong and Y. B. Park, "Effect of Intermetallic Compounds Growth Characteristics on the Shear Strength of $\mathrm{Cu}$ pillar/Sn-3.5Ag Microbump for a 3-D Stacked IC Package", Korean J. Met. Mater.,50(10), 775(2012).

8. K. Sakuma, P. S. Andry, B. Dang, J. Maria, C. K. Tsang, C. Patel, S. L. Wright, B. Webb, E. Sprogis, S. K. Kang, R. Polastre, R. Horton and J. U. Knickerbocker, "3D Chip Stacking Technology with Low-Volume Lead-Free Interconnections", Proc. 57th Electronic Components and Technology Conference (ECTC), Reno, 627, IEEE CPMT/ECA/EIA(2007).

9. Y. M. Kim, K. M. Harr and Y. H. Kim, "Mechanism of the Delayed Growth of Intermetallic Compound at the Interface between $\mathrm{Sn}-4.0 \mathrm{Ag}-0.5 \mathrm{Cu}$ and $\mathrm{Cu}-\mathrm{Zn}$ Substrate", Electron. Mater. Lett., 6, 151 (2010).

10. B. H. Lee, J. Park, S. J. Jeon, K. W. Kwon and H. J. Lee, "A Study on the Bonding Process of $\mathrm{Cu}$ Bump/Sn/Cu Bump Bonding Structure for 3D Packaging Applications", J. Electrochem. Soc., 157, 4, (2010).

11. Y. S. Lai, Y. T. Chiu and J. Chen, "Electromigration Reliability and Morphologies of $\mathrm{Cu}$ Pillar Flip-Chip Solder Joints with Cu Substrate Pad Metallization”, J. Elecron. Mater., 37, 1624 (2008).

12. M. H. Jeong, J. W. Kim, B. H. Kwak and Y. B. Park, "Effects of Annealing and Current Stressing on the Intermetallic Compounds Growth Kinetics of $\mathrm{Cu} / \mathrm{Thin} \mathrm{Sn} / \mathrm{Cu}$ Bump", Microelectron. Eng., 89, 50 (2012).

13. B. H. Kwak, M. H. Jeong and Y. B. Park, "Effects of Temperature and Current Stressing on the Intermetallic Compounds Growth Characteristics of $\mathrm{Cu}$ Pillar/Sn-3.5Ag Microbump", Jpn. J. Appl. Phys., 51, 05EE05 (2012).

14. D. R. Flanders, E. G. Jacobs and R. F. Pinizzotto, “Activation Energies of Intermetallic Growth of Sn-Ag Eutectic Solder on Copper Substrates", J. Electron. Mater., 26, 883 (1997).

15. J. W. Yoon and S. B. Jung, "Effect of Isothermal Aging on Intermetallic Compound Layer Growth at the Interface between $\mathrm{Sn}-3.5 \mathrm{Ag}-0.75 \mathrm{Cu}$ Solder and $\mathrm{Cu}$ Substrate", J. Mater.Sci., 39, 4211 (2004).

16. K. -N. Tu, Solder Joint Technology: Materials, Properties, and Reliability, pp.59-71, Springer, New York (2007).

17. D. A. Porter and K. E. Easterling, Phase Transformations in Metals and Alloys, 2nd Ed., Chapman \& Hall, London (1992). 18. T. Laurila, V. Vuorinen and J. K. Kivilahti, "Interfacial Reac- 
tions between Lead-Free Solders and Common Base Materials", Mater.Sci. Eng., R 49, 1 (2005).

19. M. H. Jeong, J. W. Kim, B. H. Kwak, B. J. Kim, G. W. Lee, J. D. Kim, Y. C. Joo and Y. B. Park, "Intermetallic Compound Growth Characteristics of $\mathrm{Cu} / \mathrm{Thin} \mathrm{Sn} / \mathrm{Cu}$ Bump for 3-D Stacked IC Package”, Kor. J. Met. Mater.,49(2), 180(2011).

20. G. T. Lim, B. J. Kim, K. W. Lee, J. D. Kim, Y. C. Joo and
Y. B. Park, "Temperature Effect on Intermetallic Compound Growth Kinetics of Cu Pillar/Sn Bumps", J. Electron. Mater., 38, 2228 (2009).

21. C. Y. Liu, Lin Ke, Y. C. Chuang and S. J. Wang, "Study of Electromigration-Induced $\mathrm{Cu}$ Consumption in the Flip-Chip Sn/Cu Solder Bumps”, J. Appl. Phys., 100, 083702 (2006). 